\title{
Research on Social Security and Charity Relief
}

\author{
Rongli Guo \\ School of Finance and public administration, Harbin University of Commerce, China, 150028
}

Keywords: Social Security; Charity Relief; Obligation of Morality

\begin{abstract}
Social security and charity relief are two basic ways to alleviate the human catastrophe, promote social welfare and improve the quality of life. It is also based on the two kinds of normative forms based on the ethical relations of human mutual assistance. The two are complementary and promote the promotion of social welfare and the realization of human happiness.
\end{abstract}

\section{Mutual Aid is an Objective Ethical Relationship}

Mutual aid is an ethical relationship with a native nature. According to Di Ji, the relationship between people is a kind of relationship, people have a relationship between each other, that they have a common need, can only be met together; they have different talents and needs, only through Mutual service in order to make themselves satisfied. Thus, if people want to survive, they must follow the laws of association. The relationship is not a rule of conduct, it is a fact that all the basic facts of human society. It is the basic fact of human society, emphasizing the originality of mutual aid, that is, it is in the process of production, exchange, distribution of the direct production of ethical attributes, is inherent in the relationship between social production and life, rather than people consciously creating ethical attributes. Hayek in the study of social freedom order, the order is divided into two categories: "spontaneous order" and "man-made order", the "spontaneous spontaneous" there is the original meaning. There is no doubt that people must be through mutual cooperation to survive and develop the existence. Everyone is an independent individual and a member of each other. The survival and development of anybody depends on the cooperation and assistance of others. In this sense, mutual aid is an ethical relationship that is objective, as opposed to the law of heaven and earth, without the consciousness of man.

Mutual aid is but a "human dependency" of a purpose of reflection, is a kind of human relations. Mutual help is the purpose of all social cooperation. The purpose of social existence is to protect and promote human survival and development, and human survival and development is to achieve a variety of objective objectives of a balanced premise. But the reality of the individual cannot be one's own power to achieve these goals, so there is the need for mutual assistance. It can be seen that the essence of mutual assistance lies in the social members through cooperation to better meet their own survival and development of the objective needs, so as to promote the comprehensive development of each person. It can be seen that mutual assistance is something that people need to pursue and realize the common needs of the individual, and is a good thing of universal desire, that is, a common good. Thus, mutual support reflects the nature of social existence and social development of the objective, inevitable, internal requirements, it is reasonable.

Mutual help is based on the social practice on the basis of the will of the form, but it is an inevitable, universal objective relationship, its conscious grasp and expression of the formation of a variety of institutional norms, with a variety of norms derived from the basic. As Hegel points out, when the ethical entity demands to become part of the free will of the actor, when the ethical order 
manifests itself as the "general behavior of the individual" and becomes the "second-day" For the fashion habits; when the ethical order through the thought was "clearly defined, and as a law of things and effective things to be published", that is real law. In short, other institutional norms are derived and inherited from the ethical relationship of this objectivity. According to Kluo Bertkin, "mutual aid has an overwhelming influence." In this connection, human life "in addition to the law of mutual competition, there are mutual rule, and this rule more than the law of mutual competition is much more important." Because of this, the role and degree of mutual assistance between people are constantly expanding and improving, and promote the evolution of human society and its system.

\section{Social Security is the Institutional form of Mutual Benefit Ethical Relations}

Mutual aid as an ethical relationship cannot be just a concept, it must be in the human production and life practice in reality, the reality of mutual aid must have dependable means and measures, and the system is such a set of human knowledge and experience to promote universal welfare for social cooperation. Because of the implementation of the system, people can generally share the results of mutual aid, human descendants to inherit the cultural heritage of the older generation, but also to ultimately promote the development of each person's own. Among them, the social security law to the authority of the law to protect the mutual help between people the stability and continuity. Social security is a system that provides financial assistance and social welfare for social members whose income is lost due to unemployment, illness, old age, and disaster. It is a "everyone for me, I am a man People "mechanism, in essence, is based on mutual aid as the cornerstone of the risk of decentralization or sharing mechanism, is an ethical social security system. Only in such a system, in order to achieve the two basic functions of mutual assistance, that is, negative functions and positive functions. Negative functions ensure that the basic conditions of human cooperation are not destroyed to ensure that the order of common life from infringement, to ensure the pursuit of the interests of the individual community. The positive function is to provide and promote the human economy, culture and social welfare, aimed at promoting the comprehensive development of human beings.

It should be said that the law recognizes the ethical relations of mutual assistance through legal rights and obligations in the form of a basic framework for the distribution of fundamental rights and obligations, the basic rules and through a series of policies, regulations, regulations and written or unwritten system and other aspects of the show, which makes the concept of mutual assistance with institutional advantages. In other words, mutual aid-based social security law, often become the basis of political, economic, cultural and other systems, penetrate into all aspects of social life, but also for the individual moral priorities and originality. Because the law has a state of lack of national coercion, any individual is faced with the system is not selective. If morality is powerless in the face of those who do not have moral consciousness and conscience and decay, then the law is behind the strong institutions of the state. Once the mutual relations of the mutual defense are recognized and protected by the law, the state's coercive force is obtained will be to a certain extent, to protect the realization of mutual assistance, and punish those who ride the car.

\section{Charity is the Moral Requirement of Mutual Benefit}

If the social security law is the recognition and protection of the ethical relations of the mutual will, then the charity is the self-reflection and conscious demand for the relationship of mutual assistance and makes it become its own habits and ways. It is the result of the "Тao" of the mutual 
aid relationship, that is, the so-called "virtuous person, too, too, too." In this sense, it can be said that ethics is the moral of the objective, or is the objective of the moral; and moral is the subject of internal ethics, or is the subjectivity of ethics, individualized. Mutualism is always based on the existence of the dualistic and multivariate principal relations of the helper and the helper. If the social security system is to emphasize the two-way rights and obligations in this relationship, then the moral is in a variety of human relations in a particular aspect of the main, is the moral requirements of this single subject In this sense, mutual aid as a paradigm of human relations, from the subjective aspect of the relationship between the parties to the point of view, it is moral norms. It is obvious that charity is the unilateral moral requirement of the subject.

Charity is the unilateral moral requirement of the helper. As moral category, charity guide and regulate moral behavior with selfless moral feelings to give the necessary care and help for each unfortunate person. In fact, every culture in the world regards charity as a basic moral norm to ask people to consciously perform their duties. Confucianism has the so-called benevolent view, Western culture to charity as a love. Zhu Xi, the Southern Song Dynasty, explained: "It is true that loyalty, pushing their own that". That is to say, in the adjustment of interpersonal relationships, on the one hand, the people should be dedicated, dedication of their own love; the other hand, For the sake of others, not demanding people, they are to push people and people in two aspects. The French philosopher Levinas regarded the love of the stranger as an unconditional responsibility. He said: "The so-called ethical order or holy order, mercy order, love order, charity order, that is, the other does not consider his position in the public, not even consider whether we have a common human nature He is concerned about making my actions; he is concerned about me as a person close to me, and regard care as a primary factor." It can be seen that the love-based charity is no longer a reciprocity of rights and obligations based on the principle of justice, but a unilateral pay, which is not prerequisiteed by the reward of the caretaker, and between the rational subjects of the same power As a prerequisite, embodies a non-reciprocal, asymmetric, non-interactive relationship, is the "goodwill of a kind of special form ".

Of course, charity as a moral requirement to the helper is at a higher level of morality and therefore cannot be enforced by law. This involves moral stratification. Kohl distinguishes between "full duty" and "incomplete obligation"; Rawls distinguishes between "responsibility" and "super-responsibility"; Fuller distinguishes between "moral of duty" and "longing for morality", and so on. We can divide our morality into two levels. The basic level is the orderly level of society. Its content is the basic moral obligation to maintain the social existence. The level of transcendence is the level of improving the quality of life. Content is the best of the exploration and pursuit. Obviously, the social security law involves the basic level of morality, and charity involves the pursuit of moral ideal and realm, is a higher level of morality. The prerequisite of social security law is to regard society as an interest partner. It emphasizes the adoption of "rules" to regulate people's mutual aid, to talk about reciprocity and return, without regard to human motivation and meaning. And charity is the community as a "big", the social relations as constituent elements of self, and seeks interpersonal sincere interaction, it can be said that this level of moral existence lies precisely in its inherent experience and Individuality, it cannot be expressed by law, nor can it be enforced by law.

In short, social security and charitable relief are based on the ethical relationship of mutual assistance in the process of mutual assistance is a kind of parallel, complementary relationship. Institutional assistance is mandatory; and charitable relief is the voluntary behavior of the public, with a voluntary. Institutional assistance to provide more employment opportunities and improve the production capacity of the poor; charitable relief is in addition to donations good, but also 
includes volunteer services, spiritual communication and other forms. Institutional aid in the state and the citizens are the obligation to fulfill and enjoy the right relationship; charity assistance in both sides is purely helpful and helped.

\section{Acknowledgements}

Fund Project: The Research Result of Hei Longjiang Province Philosophy and Social Science Fund Project: Research on the system of social assistance on the type of expenditure poverty population in Hei Longjiang Province"(15SHB02)

\section{References}

[1] Shen Zongling: Modern Western Jurisprudence [M]. Beijing: Peking University Press, 1992, P252

[2] Russia Kluo bubble gold: mutual aid theory [M]. Beijing: Commercial Press, 1963

[3] British Qi Ge Meng Baoman, and, Huan established, Li Jingtao, translated: postmodernity and its shortcomings [M]. Beijing: Xue Lin Publishing House, 2002: 56-57 